\title{
A case of ultrasound-guided erector spinae plane block using phenol for abdominal spasticity in a patient with spinal cord injury.
}

\author{
Kunie Nakajima Saiseikai Maebashi Hospital, JAPAN
}

\section{Background and aims}

Ultrasound-guided erector spinae block (ESPB) has recently been used for postoperative pain or chronic pain in abdominal area. In patients with spinal cord injury, the management of spasticity might improve patient's discomfort and quality of life. After obtaining the written consent, we planned ultrasound-guided ESPB with phenol injection for abdominal spasticity, causing dyspnea.

\section{Phenol :used to destroy peripheral nerve fibers and interrupt normal nerve impulse conduction}

\section{Case:}

The patient was a 34-year- old male with a spinal cord injury at $\mathrm{C} 4$.

He was suffering from abdominal spasticity followed by light dyspnea.

\section{Method:}

The patient was set in sitting position and the Th8-11 was obtained with ultrasound machine with $15 \mathrm{MHz}$ linear type probe. A 25-gauge, $25-\mathrm{mm}$ needle was inserted to the posterior side of transverse processes. The needle tip was directed to the plane deep to the erector spinae muscle and superficial to the transverse processes. In both site of Th8-11, 3ml of $8 \%$ phenol was injected.

ESPB is supposed to be a technique for analgesia of thoracic and abdominal wall by blocking ventral rami of spinal nerves, rami communicantes and sympathetic chain to produce visceral analgesia. It was reported that $20 \mathrm{ml}$ injection from Th5 made more than 10 vertebral levels of craniocaudal extent. To block the spasticity of abdominal and back muscles, ESPB could be applied to this treatment.

In general, Botox is often used for the treatment of spasticity and this patient also had taken botox treatment, however, it resulted in no changes.

\begin{tabular}{|c|c|c|}
\hline advantage & Easy to prepare & $\begin{array}{c}\text { Pheap (Hospital preparation) } \\
\text { Long lasting } \\
\text { No limitation for dasage }\end{array}$ \\
\hline disadvantage & $\begin{array}{c}\text { Very expensive } \\
\text { Short period effect } \\
\text { Limitation for } \\
\text { amount dosage }\end{array}$ & $\begin{array}{c}\text { Burning sensation } \\
\text { Numbness }\end{array}$ \\
\hline
\end{tabular}

\section{Ultrasound guided ESPB}
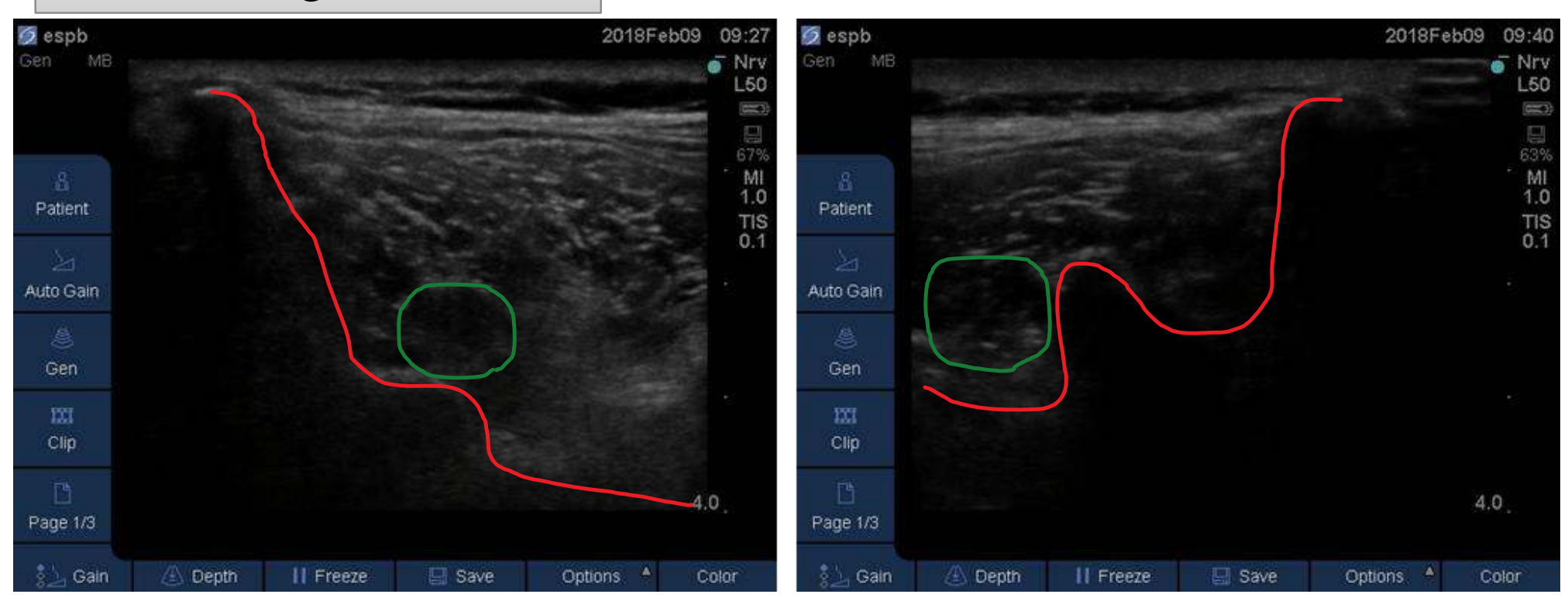
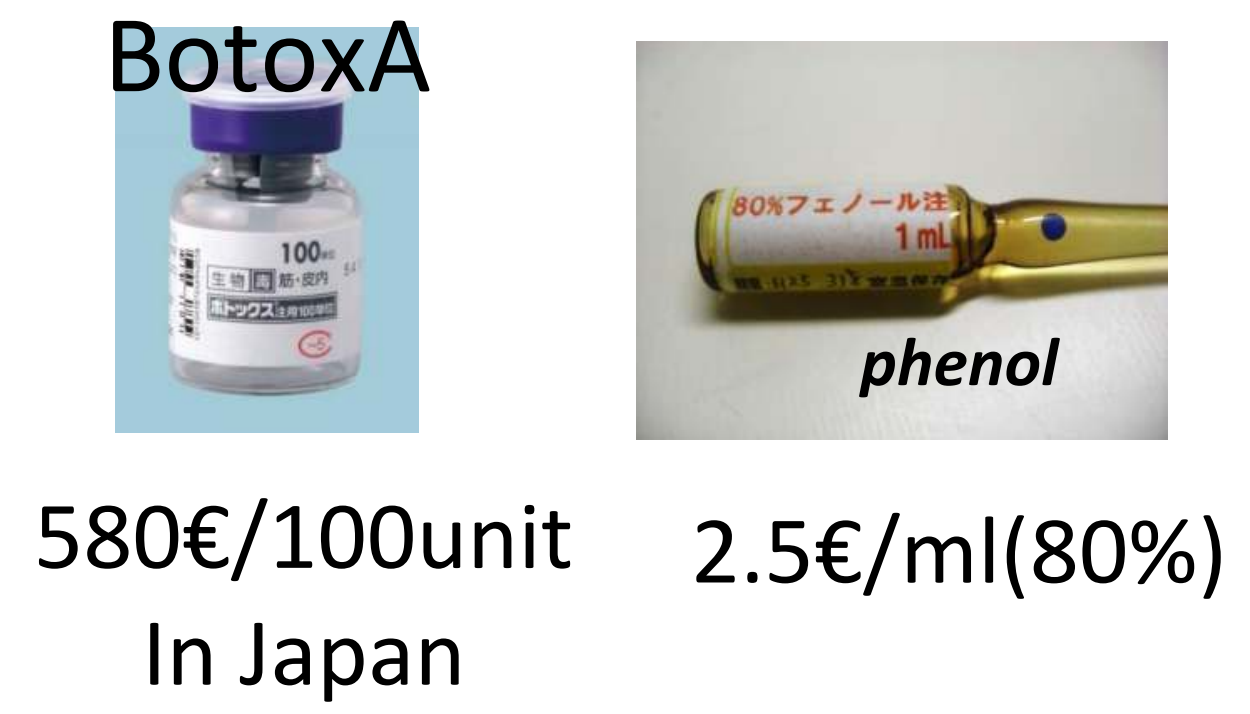

Result: Patient's self-assessment 2 weeks after the block was that spasticity of the back muscle was reduced to one-third and dyspnea had improved.

The positive effect of the block for spasticity lasted for more than 6 months.

\section{There is a limitation for evaluation of treatment effect : unable to perform examinations} (respiratory function, electromyogram) because of paraplegia.

Conclusion : Ultrasound guided ESPB with phenol for abdominal spasticity was effective for a period longer than expected. ESPB can be applied to the treatment for abdominal spasticity of spinal cord injury patients. 